\title{
Association of the Social Determinants of Health With Quality of Primary Care
}

\author{
Alan Katz, MBCbB, MSc $c^{1,2,3}$ \\ Dan Chateau, $\mathrm{PbD}^{1,3}$ \\ Jennifer E. Enns, $P b D^{1,3}$ \\ Jeff Valdivia, MNRM, CAPM ${ }^{1}$ \\ Carole Taylor, MSC ${ }^{1}$ \\ Randy Walld, BSc, BComm (Hons) ${ }^{1}$ \\ Scott McCulloch, $M A^{1}$ \\ 'Manitoba Centre for Health Policy, \\ University of Manitoba, Manitoba, Canada \\ ${ }^{2}$ Departments of Family Medicine, Univer- \\ sity of Manitoba, Manitoba, Canada \\ ${ }^{3}$ Department of Community Health \\ Sciences, University of Manitoba, \\ Manitoba, Canada
}

Conflicts of interest: authors report none.

\section{CORRESPONDING AUTHOR}

Alan Katz, MBChB, MSc Manitoba Centre for Health Policy

University of Manitoba

408-727 McDermot Ave

Winnipeg, MB R3E 3P5

alan_katz@cpe.umanitoba.ca

\begin{abstract}
PURPOSE In primary care, there is increasing recognition of the difficulty of treating patients' immediate health concerns when their overall well-being is shaped by underlying social determinants of health. We assessed the association of social complexity factors with the quality of care patients received in primary care settings.
\end{abstract}

METHODS Eleven social complexity factors were defined using administrative data on poverty, mental health, newcomer status, and justice system involvement from the Manitoba Population Research Data Repository. We measured the distribution of these factors among primary care patients who made at least 3 visits during 2010-2013 to clinicians in Manitoba, Canada. Using generalized linear mixed modeling, we measured 26 primary care indicators to compare the quality of care received by patients with 0 to 5 or more social complexity factors.

RESULTS Among 626,264 primary care patients, 54\% were living with at least 1 social complexity factor, and $4 \%$ were living with 5 or more. Social complexity factors were strongly associated with poorer outcomes with respect to primary care indicators for prevention (eg, breast cancer screening; odds ratio $[\mathrm{OR}]=0.77 ; 99 \% \mathrm{Cl}, 0.73-0.81)$, chronic disease management (eg, diabetes management; $\mathrm{OR}=0.86 ; 99 \% \mathrm{Cl}, 0.79-0.92)$, geriatric care (eg, benzodiazepine prescriptions; $\mathrm{OR}=1.63 ; 99 \% \mathrm{Cl}, 1.48-1.80)$, and use of health services (eg, ambulatory visits; $\mathrm{OR}=1.09 ; 99 \% \mathrm{Cl}, 1.08-1.09$ ).

CONCLUSIONS Linking health and social data demonstrates how social determinants are associated with primary care service provision. Our findings provide insight into the social needs of primary care populations, and may support the development of focused interventions to address social complexity in primary care.

Ann Fam Med 2018;16:217-224. https://doi.org/10.1370/afm.2236.

\section{INTRODUCTION}

$\mathrm{P}$ rimary care is a core tenet of health care in developed nations, and is widely regarded as a natural nexus for coordinating clinical care, public health, and community-based services. ${ }^{1,2}$ Widening health disparities continue to plague society, however, despite attention to integration of services across the health care spectrum. In recent years, there has been increasing recognition of the nonclinical factors affecting health namely, the social determinants of health. ${ }^{1,3}$ The World Health Organization describes the social determinants of health as the "conditions in which people are born, grow, work, live and age, and the wider set of forces and systems shaping the conditions of daily life." ${ }^{14}$ Social determinants can present a major challenge to delivering effective primary care, because they often compound the complexities in addressing patients' health concerns. ${ }^{5,6}$ This issue is recognized by primary care professionals, as $85 \%$ of respondents in a survey of 1,000 physicians found social determinants of health to play as important a role as medical needs, but many lacked the confidence to address those social needs and believed their patients' health suffered as a result. ${ }^{7}$ This impression is supported by literature showing the social determinants of health to be associated with elevated rates of morbidity, mortality, and other adverse health outcomes. ${ }^{8-11}$ 
Expanding the role of primary care professionals in addressing the social determinants of health is feasible with initiatives that invest upstream and expand the health care team..$^{12}$ In the Unites States, health systems increasingly emphasize social determinants through bundled payments, capitation funding models, and, more recently, penalties to hospitals for 30-day readmissions. ${ }^{13}$ Efforts to transform primary care delivery, such as placing more emphasis on components of the patient-centered medical home model ${ }_{1}^{14}$ have increased the capacity of primary care teams to address patients' needs in a broader interdisciplinary context. These initiatives should address concerns that primary care professionals are not compensated for incorporating the social determinants of health into practice, or that they would be operating "out of scope." Quality primary care is associated with attenuation of the harmful health effects of income inequalities, ${ }^{1,15}$ making primary care a highly appropriate environment for measuring and intervening on social determinants of health.

High-quality data are critically important for identifying underlying challenges with social determinants of health and for evaluating interventions designed to mitigate them, however, individual- and practice-level data on social determinants of health are rarely available within primary care settings, and information on the best way to collect and use these data has not been widely established. At the Manitoba Centre for Health Policy (MCHP), we have a unique resource for investigating the association of social determinants and primary care in the Manitoba Population Research Data Repository, which holds more than 30 years of linkable individual-level administrative data from health and social sectors on nearly the entire population of the Canadian province (approximately 1.3 million individuals).

To better inform strategies addressing social determinants of health in primary care, we defined 11 social complexity factors using population-based administrative data and examined the association of these factors with the quality of care received by primary care patients. We hypothesized that, because of the multilayered nature of addressing socially complex patients' health concerns, these patients would receive poorerquality care than patients living without social complexity factors. We anticipate that our findings will provide insight into the social needs of primary care populations, and support the development of focused interventions to address social complexity in primary care settings.

\section{METHODS}

This cohort study examined the association of social complexity with quality of care received by primary care patients in Winnipeg, Manitoba, Canada. The study was approved by the University of Manitoba Health Research Ethics Board and the Health Information Privacy Committee at Manitoba Health.

\section{Study Setting and Participants}

Our cohort included all 627,047 Manitoba residents who made at least 3 ambulatory visits to a primary care clinician based in the major urban center of Winnipeg (population 700,000) between April 1, 2010 and March 31, 2013. Under Manitoba's universal health care system, patients have free choice of the primary care clinician(s) they visit. We excluded those living in nursing homes (322 patients) and those not living in Manitoba for the entire study period (461 patients), for a total of 626,264 patients in the study cohort.

\section{Data Sources}

The administrative data used to identify primary care patients and define social complexity factors came from 16 health and social data sets in the Manitoba Population Research Data Repository housed at the MCHP (Supplemental Appendix 1, http://www. annfammed.org/content/16/3/217/suppl/DC1). These data are routinely collected during the administration of the universal health care system, social services, and the education and justice systems in the province. The repository includes a health registry of almost all provincial births (more than 99\% of births from Vital Statistics). Military personnel and their families, members of the Royal Canadian Mounted Police, and Indigenous groups (First Nations and Inuit populations) are federally insured, and their inclusion in the databases is variable depending on the source. The deidentified data can be linked at the individual level to conduct research within the secure MCHP environment using scrambled numeric identifiers. Data in the repository have been extensively documented and validated for this type of research. ${ }^{16-19}$ A detailed description of the data quality assessment and linkage procedures at MCHP is available elsewhere. ${ }^{20,21}$

\section{Social Complexity Factors}

We defined a set of social complexity factors related to housing, income, mental health, newcomer status, family structure, and involvement with the justice system. Selection criteria were based on literature that shows these social complexity factors are linked to poor physical and mental health outcomes. ${ }^{22-27} \mathrm{We}$ also drew heavily on the work of Schaink et al, ${ }^{6}$ who identified social determinants of health in the psychosocial dimension of patient complexity of care.

Ultimately, we assessed 11 social complexity factors: (1) high residential mobility (moved residences 
at least 3 times within 10 person-years), (2) lowincome quintile (was in the lowest area-based income quintile, ie, lowest $20 \%$ of the population), (3) social housing resident (had ever lived in a social housing residence owned and managed by Manitoba Housing), (4) income assistance (had ever received income assistance); (5) major mental health diagnosis (had ever had a diagnosis of a psychotic disorder) ${ }_{i}(6)$ newcomer (had lived in Manitoba less than 5 years and resided in a neighborhood that had a high proportion of immigrants); (7) child of a newcomer (was the child of an individual who met the definition of newcomer) (8) teen mother (female and first gave birth at the age of 19 or younger) $;$ (9) child of a teen mother (was the child of an individual who met the definition of teen mother) ${ }_{i}(10)$ in care of Child Welfare Services (was aged 0 to 18 at the end of the study period and had been removed from their family of origin and placed in care of another adult because of concern about provision of care in the family of origin); and (11) involved with justice system (had contact with the justice system as a witness, a victim, or an accused of a crime).

\section{Main Outcome: Quality of Primary Care}

We used a total of 26 primary care quality indicators to assess the care that patients received. Previous research has identified these indicators as important measures of quality of care in family practice, ${ }^{28}$ and demonstrated that they can be assessed using administrative data. ${ }^{29-31}$ Three of the quality indicators (colorectal cancer screening for adults aged 50 to 74 years; radiograph for low back pain for adults aged 20 years and older; and emergency department visit rate for patients having a Canadian Triage and Acuity Scale rating of 4 or 5) were developed at MCHP for this study based on current literature highlighting their relevance to high-quality primary care. ${ }^{32-34}$

\section{Statistical Analyses}

We used generalized linear mixed models to assess the association of number of social complexity factors with primary care quality. These models accounted for the clustering of patients by physician and the resulting correlated observations. Using a logit link and binary distribution, the models were multilevel logistic regression analyses that produced robust odds ratios (ORs) comparing individuals with 1 to 5 or more social complexity factors against those with none. Contrast statements were included in the regression models to assess the linear trend of number of social complexity factors with the odds of the outcome(s). All models included sex, age, income, and morbidity level as covariates. Morbidity was assessed using resource utilization bands (RUBs), which are derived from the Johns
Hopkins Adjusted Clinical Group Case-Mix System. ${ }^{35}$ RUBs are a simplified ranking system of a person's overall morbidity from 0 to 5 , taking into account all diagnoses attributed to him/her during medical visits and hospitalizations in the preceding year. Diagnoses are grouped together on the basis of the level of resources necessary for delivering health care for those conditions. These categories include minor illnesses (eg, chicken pox $)_{i}$ more severe but time-limited conditions (eg, broken leg); chronic illnesses (eg, diabetes); illnesses resulting from structural problems that are generally not curable (eg, cerebral palsy); and psychosocial conditions (eg, depressive disorders). ${ }^{35}$

To address multiple comparisons, we used an $\alpha$ of .01 to assess statistical significance. As many quality outcomes correlated with each other, using strict Bonferroni correction would have been too conservative. All analyses were hypothesis driven and prespecified. Data management, programming, and analyses were conducted using SAS version 9.3 (SAS Institute).

\section{RESULTS}

Characteristics of our study cohort are presented in Table 1. The final cohort consisted of 626,264 Manitobans (53\% female). As expected, patients were evenly

\section{Table 1. Characteristics of the Study Cohort $(\mathrm{N}=626,264)$}

\begin{tabular}{lc}
\hline Characteristic & Patients, No. (\%) \\
\hline Sex & $293,722(46.9)$ \\
Male & $332,542(53.1)$ \\
Female & \\
Age, Y & $49,422(7.9)$ \\
0-5 & $84,973(13.6)$ \\
$6-18$ & $231,096(36.9)$ \\
19-44 & $177,176(28.3)$ \\
$45-64$ & $44,273(7.1)$ \\
$65-74$ & $39,304(6.3)$ \\
$\geq 75$ & \\
Income & \\
Q1 $(\$ 14,772-\$ 49,509)$ & $127,638(20.4)$ \\
Q2 (\$49,510-\$63,661) & $121,591(19.4)$ \\
Q3 (\$63,662-\$79,531) & $119,853(19.1)$ \\
Q4 (\$79,532-\$98,953) & $127,495(20.4)$ \\
Q5 (\$98,954-\$343,154) & $122,731(19.6)$ \\
Unknown & $6,956(1.1)$ \\
Morbidity (RUB) & \\
0-1 & $236,016(37.7)$ \\
2 & \\
\hline In 2013 Canadian dollars. & \\
\hline
\end{tabular}


distributed across income quintiles, and the majority (70\%) had moderate morbidity levels (RUB 2 or 3 ). Figure 1 shows the prevalence of the 11 social complexity factors in the study cohort and the distribution of patients according to number of factors. Slightly more than one-half (54\%) of the study cohort were living with at least 1 social complexity factor ${ }_{i} 4 \%$ were living with 5 or more of them.

Associations between the number of social complexity factors and indicators of the quality of primary care are presented in Table 2. We observed several highly significant associations. When patients living without social complexity factors were the comparator group, there was a downward trend in the odds of receiving appropriate prevention and screening care as number of social complexity factors increased. In other words, the more factors a patient was living with, the less likely he or she was to receive, for example, a mammogram or vaccinations. Conversely, there was an upward trend in patients' odds of using health services as their number of social complexity factors increased, relative to patients living without any. Stated another way, the more factors a patient was living with, the more likely he or she was to seek ambulatory or emergency care. Even patients living with only 1 social complexity factor had a sizable reduction in the odds of breast cancer screening (OR $=0.77$; 99\% CI, 0.73 $0.81)$ and a substantial increase in the odds of ambulatory visits $(\mathrm{OR}=1.09$; 99\% $\mathrm{CI}, 1.08-1.09)$.

Not shown in Table 2 is continuity of care, which we assessed as a continuous measure using the BiceBoxerman continuity of care index. ${ }^{36}$ The index measures both the frequency of ambulatory visits and the dispersion of visits among different clinicians. Values range from 0 to 1 , where 0 indicates that all visits were made to different clinicians, and 1 indicates that all visits were made to a single clinician. In our study, patients with no social complexity factors had an average index of $0.53(99 \% \mathrm{CI}, 0.50-0.56)$, and the index decreased by an average of about 0.01 with each addi-

\section{Figure 1. Prevalence of individual social complexity factors and distribution of patients according to number of factors.}

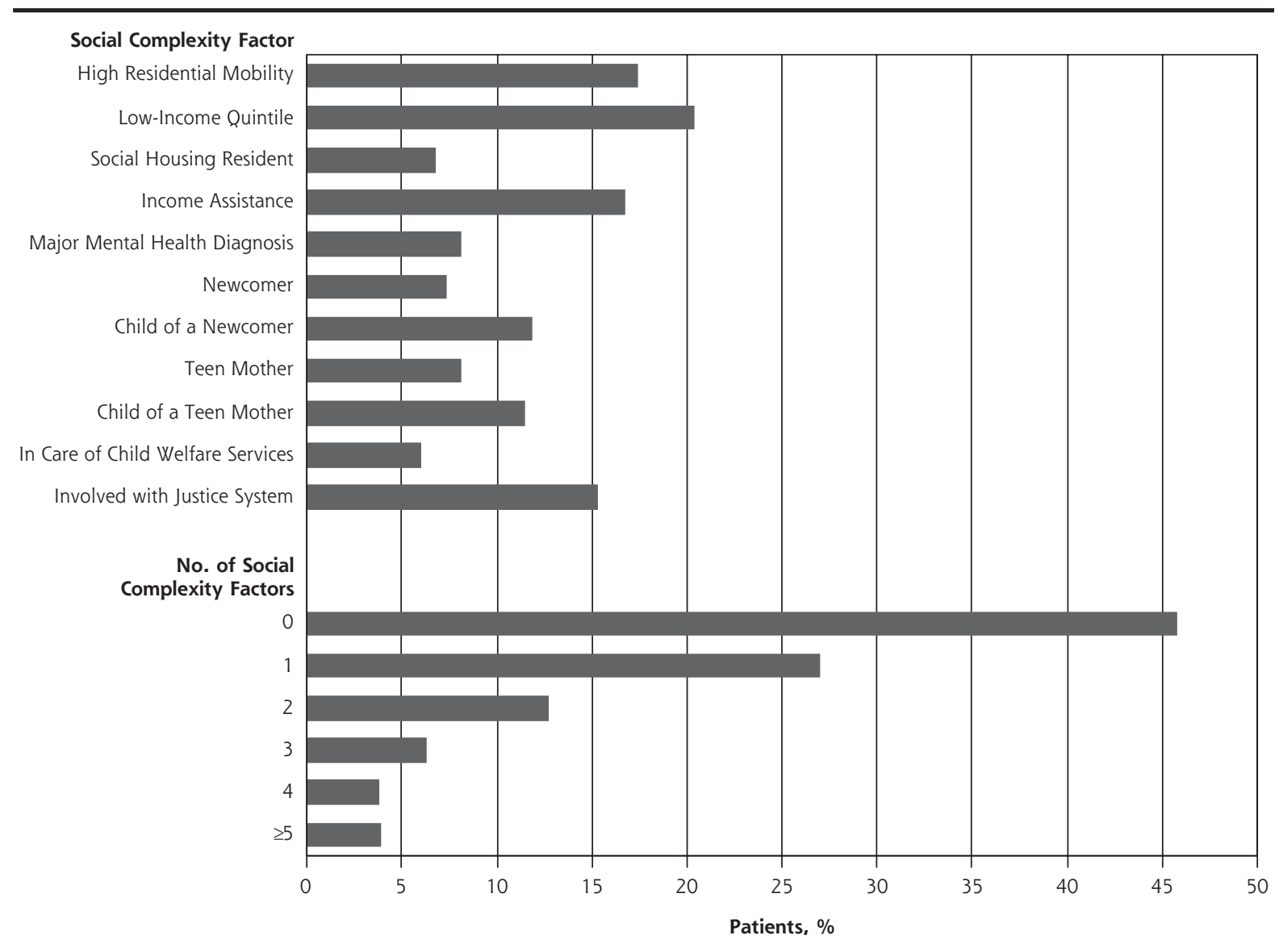

Notes: Analyses based on entire study cohort ( $N=626,264)$, except for teen mother (restricted to female patients, $N=332,542$ ); in care of Child Welfare Services (restricted to youth $\leq 18 \mathrm{y}, \mathrm{N}=134,415$ ); and child of a newcomer (restricted to newcomers $\leq 18 \mathrm{y}, \mathrm{N}=125,624$ ). See Methods for definitions of social complexity factors. 
Table 2. Association of Social Complexity Factors With Indicators of the Quality of Primary Care

\begin{tabular}{|c|c|c|c|c|c|c|}
\hline \multirow[b]{2}{*}{ Quality Indicator } & \multicolumn{5}{|c|}{ Likelihood of Receipt, Odds Ratio $(99 \% \mathrm{Cl})^{\mathrm{a}}$} & \multirow{2}{*}{$\begin{array}{c}P \\
\text { Value }\end{array}$} \\
\hline & 1 Factor & 2 Factors & 3 Factors & 4 Factors & $\geq 5$ Factors & \\
\hline \multicolumn{7}{|l|}{ Prevention and screening } \\
\hline $\begin{array}{l}\text { Breast cancer screening } \\
\text { (women 50-74 y) }\end{array}$ & $0.77(0.73-0.81)$ & $0.54(0.50-0.58)$ & $0.38(0.34-0.42)$ & $0.28(0.24-0.33)$ & $0.22(0.18-0.27)$ & $<.001$ \\
\hline $\begin{array}{l}\text { Cervical cancer screening } \\
\text { (women 21-69 y) }\end{array}$ & $1.04(1.00-1.08)$ & $0.96(0.92-1.01)$ & $0.87(0.81-0.92)$ & $0.94(0.87-1.02)$ & $1.01(0.93-1.09)$ & .003 \\
\hline $\begin{array}{l}\text { Colorectal cancer screen- } \\
\text { ing (adults 50-74 y) }\end{array}$ & $0.83(0.80-0.86)$ & $0.66(0.63-0.70)$ & $0.51(0.47-0.56)$ & $0.40(0.35-0.46)$ & $0.36(0.30-0.44)$ & .001 \\
\hline $\begin{array}{l}\text { Completed vaccinations } \\
\text { at } 2 \text { y }\end{array}$ & $0.70(0.61-0.81)$ & $0.55(0.46-0.66)$ & $0.41(0.33-0.50)$ & $0.33(0.26-0.43)$ & $0.26(0.19-0.36)$ & $<.001$ \\
\hline $\begin{array}{l}\text { Annual influenza vaccina- } \\
\text { tion (adults } \geq 65 \mathrm{y} \text { ) }\end{array}$ & $0.88(0.83-0.93)$ & $0.74(0.68-0.82)$ & $0.69(0.59-0.81)$ & $0.68(0.52-0.89)$ & $1.17(0.76-1.79)$ & $<.001$ \\
\hline $\begin{array}{l}\text { Annual influenza vaccina- } \\
\text { tion (total respiratory } \\
\text { morbidity) }\end{array}$ & $0.84(0.80-0.87)$ & $0.75(0.70-0.79)$ & $0.74(0.69-0.80)$ & $0.67(0.61-0.74)$ & $0.64(0.58-0.71)$ & .02 \\
\hline $\begin{array}{l}\text { Pneumococcal vaccina- } \\
\text { tion (adults } \geq 65 \mathrm{y} \text { ) }\end{array}$ & $0.95(0.90-1.01)$ & $0.88(0.80-0.97)$ & $0.90(0.76-1.07)$ & $0.90(0.69-1.18)$ & $0.90(0.59-1.39)$ & .001 \\
\hline \multicolumn{7}{|l|}{ Chronic disease management } \\
\hline $\begin{array}{l}\text { Diabetes management: } \\
\text { eye examination }\end{array}$ & $0.86(0.79-0.92)$ & $0.78(0.70-0.87)$ & $0.70(0.61-0.82)$ & $0.69(0.58-0.84)$ & $0.52(0.42-0.64)$ & $<.001$ \\
\hline $\begin{array}{l}\text { CHF management: initia- } \\
\text { tion of ACE inhibitor }\end{array}$ & $0.90(0.73-1.11)$ & $0.72(0.53-0.99)$ & $0.80(0.50-1.29)$ & $0.59(0.32-1.09)$ & $0.41(0.19-0.88)$ & $<.001$ \\
\hline $\begin{array}{l}\text { CHF management: persis- } \\
\text { tence of ACE inhibitor }\end{array}$ & $0.85(0.69-1.05)$ & $0.77(0.56-1.05)$ & $0.63(0.39-1.01)$ & $0.74(0.40-1.36)$ & $0.27(0.11-0.63)$ & .045 \\
\hline $\begin{array}{l}\text { Post-MI management: } \\
\text { initiation of } \beta \text {-blocker }\end{array}$ & $1.16(0.76-1.77)$ & $0.80(0.45-1.43)$ & $0.96(0.39-2.37)$ & $0.30(0.12-0.76)$ & $0.48(0.14-1.67)$ & .04 \\
\hline $\begin{array}{l}\text { Post-MI management: } \\
\text { persistence of } \beta \text {-blocker }\end{array}$ & $0.97(0.72-1.31)$ & $0.77(0.50-1.19)$ & $0.75(0.40-1.39)$ & $0.66(0.29-1.52)$ & $0.94(0.34-2.66)$ & .65 \\
\hline $\begin{array}{l}\text { Post-MI management: } \\
\text { initiation of statin }\end{array}$ & $0.87(0.64-1.17)$ & $0.81(0.52-1.25)$ & $0.63(0.34-1.19)$ & $0.43(0.19-0.98)$ & $0.91(0.31-2.69)$ & .02 \\
\hline $\begin{array}{l}\text { Post-MI management: } \\
\text { persistence of statin }\end{array}$ & $0.75(0.56-1.01)$ & $0.76(0.49-1.16)$ & $0.49(0.26-0.92)$ & $0.46(0.20-1.05)$ & $0.82(0.30-2.24)$ & .004 \\
\hline $\begin{array}{l}\text { Asthma management: } \\
\text { medication use }\end{array}$ & $0.90(0.82-0.99)$ & $0.90(0.80-1.01)$ & $0.81(0.71-0.94)$ & $0.81(0.69-0.96)$ & $0.88(0.75-1.04)$ & .001 \\
\hline \multicolumn{7}{|l|}{ Medications } \\
\hline $\begin{array}{l}\text { Benzodiazepine prescrip- } \\
\text { tion (community-dwell- } \\
\text { ing adults } \geq 75 \mathrm{y} \text { ) }\end{array}$ & $1.63(1.48-1.80)$ & $2.16(1.82-2.56)$ & $3.15(2.25-4.40)$ & $3.03(1.36-6.71)$ & $3.08(0.68-14.00)$ & $<.001$ \\
\hline $\begin{array}{l}\text { Beers List drug prescrip- } \\
\text { tion (community-dwell- } \\
\text { ing adults } \geq 65 \text { y) }\end{array}$ & $1.39(1.31-1.47)$ & $1.92(1.74-2.12)$ & $2.37(2.01-2.79)$ & $3.50(2.67-4.60)$ & $4.05(2.61-6.28)$ & $<.001$ \\
\hline $\begin{array}{l}\text { Depression care: prescrip- } \\
\text { tion follow-up }\end{array}$ & $1.07(0.90-1.28)$ & $1.09(0.88-1.35)$ & $1.09(0.83-1.42)$ & $1.21(0.89-1.64)$ & $1.46(1.08-1.99)$ & .004 \\
\hline \multicolumn{7}{|l|}{ Health services use } \\
\hline $\begin{array}{l}\text { Hospitalizations for ACSC } \\
\quad \text { (adults } \geq 74 \text { y) }\end{array}$ & $1.43(1.11-1.84)$ & $2.40(1.77-3.24)$ & $3.58(2.52-5.08)$ & $4.80(3.24-7.11)$ & $5.64(3.70-8.60)$ & $<.001$ \\
\hline $\begin{array}{l}\text { Radiograph for low back } \\
\text { pain (adults } \geq 20 \mathrm{y} \text { ) }\end{array}$ & $0.92(0.73-1.15)$ & $1.02(0.76-1.37)$ & $0.80(0.54-1.18)$ & $0.83(0.50-1.37)$ & $1.10(0.68-1.80)$ & .34 \\
\hline $\begin{array}{l}\text { Hospital episodes with } \\
\text { readmission within } 30 \mathrm{~d}\end{array}$ & $1.23(1.11-1.36)$ & $1.41(1.25-1.60)$ & $1.86(1.62-2.15)$ & $1.91(1.63-2.24)$ & $2.21(1.89-2.58)$ & $<.001$ \\
\hline $\begin{array}{l}\text { ED visits for low-acuity } \\
\left.\text { (CTAS } 4 \text { and } 5^{c}\right) \text { patients }\end{array}$ & $1.21(1.17-1.24)$ & $1.54(1.50-1.60)$ & $2.02(1.95-2.10)$ & $2.61(2.51-2.72)$ & $3.38(3.24-3.51)$ & $<.001$ \\
\hline $\begin{array}{l}\text { Ambulatory visits to pri- } \\
\text { mary care }\end{array}$ & 1.09 (1.08-1.09) & $1.19(1.19-1.20)$ & $1.29(1.28-1.29)$ & $1.41(1.40-1.42)$ & $1.62(1.61-1.62)$ & .001 \\
\hline $\begin{array}{l}\text { Ambulatory visits for } \\
\text { patients with RUB of } 3 \text {, } \\
4 \text {, or } 5\end{array}$ & $1.11(1.09-1.13)$ & $1.26(1.23-1.29)$ & $1.44(1.36-1.51)$ & $1.70(1.55-1.86)$ & $2.12(1.88-2.39)$ & $<.001$ \\
\hline $\begin{array}{l}\text { Ambulatory visits with } \\
\text { a call to health tele- } \\
\text { phone service within } \\
2 \mathrm{~d} \text { of visit }\end{array}$ & $1.02(0.97-1.06)$ & $1.14(1.08-1.20)$ & $1.33(1.25-1.42)$ & $1.53(1.43-1.64)$ & $1.75(1.63-1.87)$ & $<.001$ \\
\hline \multicolumn{7}{|c|}{$\begin{array}{l}\text { ACE = angiotensin-converting enzyme; } \mathrm{ACSC}=\text { ambulatory care-sensitive conditions; } \mathrm{CHF}=\text { congestive heart failure; } \mathrm{CTAS}=\text { Canadian Triage Acuity Scale; } E D=\text { emer- } \\
\text { gency department; } \mathrm{MI}=\text { myocardial infarction; RUB = resource utilization band. }\end{array}$} \\
\hline \multicolumn{7}{|c|}{ Note: Adjusted for sex, age, income quintile, and morbidity level (RUB). } \\
\hline $\begin{array}{l}\text { a Compared with patients having } \\
\text { b For trend across factor categorie } \\
\text { c On a scale of } 1 \text { to } 5 \text {, with } 5 \text { bein }\end{array}$ & $\begin{array}{l}\text { social complexity fact } \\
\text { owest acuity. }\end{array}$ & & & & & \\
\hline
\end{tabular}


tional social complexity factor. For example, the continuity of care index was 0.52 (99\% CI, 0.49-0.55) with 1 social complexity factor, $0.51(99 \% \mathrm{CI}, 0.48-0.54)$ with 2 factors, and 0.50 (99\% CI, $0.40-0.53)$ with 3 factors, and this linear trend was significant $(P<.001)$.

Compared with peers having none, patients having more social complexity factors also had worse outcomes for some of the chronic disease management indicators, such as diabetes management (receiving an eye examination) and congestive heart failure management (initiating angiotensin-converting enzyme inhibitor therapy). Indicators of medical care for community-dwelling older adults, including prescribing of benzodiazepine and Beers List drugs (those potentially inappropriate for this age-group), also showed an upward-trending association with number of social complexity factors. Even patients living with only a single social complexity factor had a sizable reduction in the odds of receiving an eye examination as part of their diabetes management $(\mathrm{OR}=0.86 ; 99 \% \mathrm{CI}, 0.79$ 0.92) and a sizable increase in the odds of benzodiazepine prescriptions among geriatric patients $(\mathrm{OR}=1.63$; 99\% CI, 1.48-1.80).

\section{DISCUSSION}

This study demonstrates how linking secondary data from the health and social sectors can provide insight into the underlying role of social determinants in influencing health care delivery and patient outcomes. Our findings show the pervasive nature of the social challenges faced by the primary care patient population; slightly more than one-half of our study cohort were living with some degree of social complexity, and this disadvantage had a nearly universal negative impact on the quality of care they received. For the majority of the 26 primary care quality indicators we measured, an increasing number of social complexity factors was associated with poorer outcomes.

\section{Findings in Context}

Recent health system reform in Canada and the United States has recognized the importance of addressing the needs of complex, high-needs patients. Although the primary care quality indicators we used in our study do not specifically address the $5 \%$ of the population who have been shown to account for $60 \%$ or more of health care costs, ${ }^{37-39}$ we have developed administrative data definitions to identify a population of patients who are likely to contribute disproportionately to health care costs and primary care professional workload. By defining the specific social complexities that affect the health of this population, our study provides evidence underscoring the importance of developing and using interventions to address future health care needs. The imperative for addressing these issues goes beyond the financial costs of care, as social justice dictates that society take action on these glaring health disparities. ${ }^{40,41}$

Access to high-quality individual-level or practicelevel data on the social determinants of health is critical for research focused on health inequities in primary care. A number of recent studies have demonstrated the use of primary and secondary data in this context. Administering brief surveys in primary care settings to flag patients' key social complexity factors has been shown to be feasible and acceptable to patients and clinicians ${ }_{r}^{42,43}$ and has spurred the development of interventions to link patients with resources and services in their communities. ${ }^{44,45}$ The necessary integration of these data into electronic medical records is in many cases still too limited to provide contextual information for clinical decision making and the organization of care, however. ${ }^{1,42}$ Analyses of secondary socioeconomic status data, such as those available in the Manitoba Population Research Data Repository at MCHP, can mitigate some of the cost of, and time required for, primary data collection. This repository makes large representative patient cohorts available for research purposes, granting us the ability to develop definitions for the social determinants of health and measure new indicators of primary care quality. The individuallevel data and cross-sector linkage capabilities of the repository allow for analyses of unparalleled depth and breadth. Although data collected for administrative purposes are not always research ready, the data in MCHP's repository undergo rigorous quality assessment to minimize biases related to misclassification or missing data. ${ }^{20}$ In jurisdictions where administrative data repositories lack the breadth and depth needed for holistic analyses of social determinants, using geospatial technologies to link neighborhood-level socioeconomic data (eg, census data) to patient addresses in electronic medical records may prove valuable. ${ }^{46,47}$

\section{Limitations}

Despite the many strengths of this study and the administrative data on which it is based, there are some limitations that must be acknowledged. Although income quintiles are a widely accepted measure of socioeconomic status, one consequence of using the first quintile to define people as having low income is that $20 \%$ of the study cohort falls into this category by definition. We found, however, that this proportion was comparable to another widely used and validated measure of poverty, the low-income cutoff, a threshold below which families devote a larger share of their income to household necessities. ${ }^{48}$ There 
are a number of behaviors related to poor health, such as substance misuse, that would likely have been important indicators of social complexity in primary care. Although we did not define substance misuse as a social complexity factor (because of concerns about underreporting and resulting issues with administrative data quality), health behaviors are accounted for in the RUB morbidity measure insofar as they are captured by clinical diagnosis codes. Likewise, variables describing access to care, including transportation barriers and hours of operation of primary care clinics, were not available to us in the administrative data. Additionally, this study examines quality of primary care in an urban population, although the findings are widely generalizable to other urban settings ${ }_{1}{ }^{17}$ further research is required to examine whether a similar relationship between social complexity and quality of primary care exists in rural and remote communities.

\section{Practice and Policy Implications}

Our findings highlight striking differences in social complexity across the primary care patient population and show the higher demands placed on primary care clinicians caring for socially complex patients. We have also identified the specific social needs of primary care patients. The potential for ensuring patients receive care in their home practices now exists, thereby making it possible to identify specific interdisciplinary team members best suited to individual practices. Expanding interdisciplinary team-based models of care and exploring alternative funding models that acknowledge the greater complexity of addressing the social determinants of health in the primary care setting could help to achieve better health equity for vulnerable patient populations.

To read or post commentaries in response to this article, see it online at http://www.AnnFamMed.org/content/16/3/217.

Key words: primary care; social determinants of health; quality of care; administrative data; personalized medicine; vulnerable populations; health care disparities; social medicine; practice-based research

Submitted October 4, 2017; submitted, revised, January 22, 2018; accepted March 6, 2018

Funding support: This study was funded as part of a 5-year contract between the Manitoba Centre for Health Policy and the Government of Manitoba.

Disclaimer: The funders had no input into the study design, implementation, or interpretation of the findings. The conclusions are those of the authors alone, and no official endorsement by the funders was intended or should be inferred.

Previous presentations: This study was presented at the Canadian Association of Health Services and Policy Research (CAHSPR) meetings on May 27, 2015; Toronto, Canada, and May 29, 2016; Montreal, Que- bec, Canada, and at the International Population Data Linkage Network meeting on August 28, 2016; Wales, United Kingdom.

Acknowledgments: The data for this study were provided by the Manitoba Government Department of Health, Seniors \& Active Living; the Winnipeg Regional Health Authority; CancerCare Manitoba; Manitoba Families, Manitoba Justice; and the Vital Statistics Agency under Health Information Privacy Committee No. 2013/2014-29.

Supplementary materials: Available at http://www. AnnFamMed. org/content/16/3/217/suppl/DC1/

\section{References}

1. DeVoe JE, Bazemore AW, Cottrell EK, et al. Perspectives in primary care: a conceptual framework and path for integrating social determinants of health into primary care practice. Ann Fam Med. 2016;14(2):104-108.

2. International Conference on Primary Health Care. Declaration of Alma-Ata. WHO Chron. 1978;32(11):428-430.

3. McGinnis JM, Williams-Russo P, Knickman JR. The case for more active policy attention to health promotion. Health Aff (Millwood). 2002;21(2):78-93

4. World Health Organization. World Conference on Social Determinants of Health: Case studies on social determinants. 2014. http:// www.who.int/sdhconference/resources/case_studies/en/. Accessed Apr 18, 2017.

5. Do Johnson R. "complex needs" need "complex needs services"? part one. Ment Health Social Incl. 2013;17(3):127-134.

6. Schaink AK, Kuluski K, Lyons RF, et al. A scoping review and thematic classification of patient complexity: offering a unifying framework. J Comorb. 2012;2:1-9.

7. Fenton M. Health care's blind side: the overlooked connection between social needs and good health. The Robert Wood Johnson Foundation. https://www.rwjf.org/en/library/research/2011/12/ health-care-s-blind-side.html. Published Dec 1, 2011. Accessed Apr 18, 2017.

8. Galobardes B, Davey Smith G, Jeffreys M, McCarron P. Childhood socioeconomic circumstances predict specific causes of death in adulthood: the Glasgow student cohort study. J Epidemiol Community Health. 2006;60(6):527-529.

9. Chandola T, Ferrie J, Sacker A, Marmot M. Social inequalities in self reported health in early old age: follow-up of prospective cohort study. BMJ. 2007;334(7601):990.

10. Danaei G, Ding EL, Mozaffarian D, et al. The preventable causes of death in the United States: comparative risk assessment of dietary, lifestyle, and metabolic risk factors. PLoS Med. 2009;6(4): e1000058.

11. Hämmig O, Bauer GF. The social gradient in work and health: a cross-sectional study exploring the relationship between working conditions and health inequalities. BMC Public Health. 2013;13:1170.

12. Aery $A$, Rucchetto $A$, Singer $A$, et al. Implementation and impact of an online tool used in primary care to improve access to financial benefits for patients: a study protocol. BMJ Open. 2017;7(10): e015947.

13. Kaufman A. Theory vs practice: Should primary care practice take on social determinants of health now? Yes. Ann Fam Med. 2016;14(2):100-101.

14. Bodenheimer T, Ghorob A, Willard-Grace R, Grumbach K. The 10 building blocks of high-performing primary care. Ann Fam Med. 2014;12(2):166-171.

15. Gottlieb LM, Tirozzi KJ, Manchanda R, Burns AR, Sandel MT. Moving electronic medical records upstream: incorporating social determinants of health. Am J Prev Med. 2015;48(2):215-218. 
16. Roos LL, Nicol JP. A research registry: uses, development, and accuracy. J Clin Epidemiol. 1999;52(1):39-47.

17. Roos LL, Brownell M, Lix L, Roos NP, Walld R, MacWilliam L. From health research to social research: privacy, methods, approaches. Soc Sci Med. 2008;66(1):117-129.

18. Roos LL, Gupta S, Soodeen RA, Jebamani L. Data quality in an information-rich environment: Canada as an example. Can J Aging. 2005;24(Suppl 1):153-170.

19. Katz A, De Coster C, Bogdanovic B, Soodeen R, Chateau D. Using Administrative Data to Develop Indicators of Quality in Family Practice. Winnipeg, Manitoba, Canada: Manitoba Centre for Health Policy; 2004.

20. Smith M, Lix LM, Azimaee M, et al. Assessing the quality of administrative data for research: a framework from the Manitoba Centre for Health Policy. J Am Med Inform Assoc. 2017;0cx078.

21. Manitoba Centre for Health Policy. Record Linkage in Manitoba. http://mchp-appserv.cpe.umanitoba.ca/viewConcept. php?conceptID = 1363. Published Feb 24, 2014. Accessed Apr 18, 2017.

22. Hanson JL, Hair N, Shen DG, et al. Family poverty affects the rate of human infant brain growth. PLOS ONE. 2013;8(12):e80954.

23. Hayward E, Ibe C, Young JH, et al. Linking social and built environmental factors to the health of public housing residents: a focus group study. BMC Public Health. 2015;15:351.

24. Lipman EL, Georgiades K, Boyle MH. Young adult outcomes of children born to teen mothers: effects of being born during their teen or later years. J Am Acad Child Adolesc Psychiatry. 2011;50(3): 232-241.e4.

25. Spencer N, Strazdins L. Socioeconomic disadvantage and onset of childhood chronic disabling conditions: a cohort study. Arch Dis Child. 2015;100(4):317-322.

26. Sword W, Watt S, Krueger P. Postpartum health, service needs, and access to care experiences of immigrant and Canadian-born women. J Obstet Gynecol Neonatal Nurs. 2006;35(6):717-727.

27. Brownell MD, Roos NP, MacWilliam L, Leclair L, Ekuma O, Fransoo R. Academic and social outcomes for high-risk youths in Manitoba. Can J Educ. 2010;33(4):804-836.

28. Canadian Institute for Health Information. Pan-Canadian Primary Health Care Indicator Update Report. https://secure.cihi.ca/free products/Pan-Canadian_PHC_Indicator_Update_Report_en_web. pdf. Published 2012. Accessed Apr 18, 2017.

29. Katz A, Soodeen RA, Bogdanovic B, De Coster C, Chateau D. Can the quality of care in family practice be measured using administrative data? Health Serv Res. 2006;41(6):2238-2254.

30. Green ME, Hogg W, Savage C, et al. Assessing methods for measurement of clinical outcomes and quality of care in primary care practices. BMC Health Serv Res. 2012;12:214.

31. Campbell SM, Braspenning J, Hutchinson A, Marshall M. Research methods used in developing and applying quality indicators in primary care. Qual Saf Health Care. 2002;11(4):358-364.

32. Bacchus CM, Dunfield L, Gorber SC, et al; Canadian Task Force on Preventive Health Care. Recommendations on screening for colorectal cancer in primary care. CMAJ. 2016;188(5):340-348.
33. Choosing Wisely Canada. Eleven things physician and patients should question. http://www.choosingwiselycanada.org/recommendations/family-medicine/. Published 2014. Accessed Apr 17, 2017.

34. Ontario Ministry of Health and Long-Term Care. Emergency visits for conditions that could be treated in alternative primary care setting: Resource for Indicator Standards (RIS). http://www.health.gov. on.ca/en/pro/programs/ris/docs/emergency_visits_that_could_be_ treated_in_alternative_primary_care_setting_en.pdf. Published Mar 10, 2016. Accessed Apr 17, 2017.

35. The Johns Hopkins University Bloomberg School of Public Health. The Johns Hopkins ACG Case-Mix System Documentation \& Application Manual, Version 11. Baltimore, MD: Johns Hopkins University; 2014.

36. Bice TW, Boxerman SB. A quantitative measure of continuity of care. Med Care. 1977;15(4):347-349.

37. Wodchis WP, Austin PC, Henry DA. A 3-year study of high-cost users of health care. CMAJ. 2016;188(3):182-188.

38. Rais S, Nazerian A, Ardal S, Chechulin Y, Bains N, Malikov K. Highcost users of Ontario's healthcare services. Healthc Policy. 2013;9(1): 44-51.

39. Hayes SL, Salzberg CA, McCarthy D, et al. High-need, highcost patients: who are they and how do they use health care? A population-based comparison of demographics, health care use, and expenditures. Issue Brief (Commonw Fund). 2016;26:1-14.

40. Commission on Social Determinants of Health. Closing the Gap in a Generation: Health Equity Through Action on the Social Determinants of Health. Final Report of the Commission on Social Determinants of Health. Geneva, Switzerland: World Health Organization; 2008.

41. World Health Organization. World Health Report 2008: Primary Health Care: Now More Than Ever. Geneva, Switzerland: World Health Organization; 2008.

42. Glowa PT, Olson AL, Johnson DJ. Screening for adverse childhood experiences in a family medicine setting: a feasibility study. J Am Board Fam Med. 2016;29(3):303-307.

43. Page-Reeves J, Kaufman W, Bleecker $M$, et al. Addressing social determinants of health in a clinic setting: The WellRx Pilot in Albuquerque, New Mexico. J Am Board Fam Med. 2016;29(3):414-418.

44. Pinto AD, Glattstein-Young G, Mohamed A, Bloch G, Leung F-H, Glazier RH. Building a foundation to reduce health inequities: routine collection of sociodemographic data in primary care. J Am Board Fam Med. 2016;29(3):348-355.

45. Lofters AK, Schuler A, Slater M, et al. Using self-reported data on the social determinants of health in primary care to identify cancer screening disparities: opportunities and challenges. BMC Fam Pract. 2017;18(1):31.

46. Hughes LS, Phillips RL Jr, DeVoe JE, Bazemore AW. Community vital signs: taking the pulse of the community while caring for patients. J Am Board Fam Med. 2016;29(3):419-422.

47. Li V, McBurnie MA, Simon M, et al. Impact of social determinants of health on patients with complex diabetes who are served by national safety-net health centers. J Am Board Fam Med. 2016;29(3): 356-370.

48. Statistics Canada. Low income cut-offs. 2018. https://www.statcan. gc.ca/pub/75f0002m/2012002/lico-sfr-eng.htm. Modified Nov 27, 2015. Accessed Jan 18, 2018. 